\title{
Endoscopic management of colocolic intussusception in an adult with colonic stent placement
}

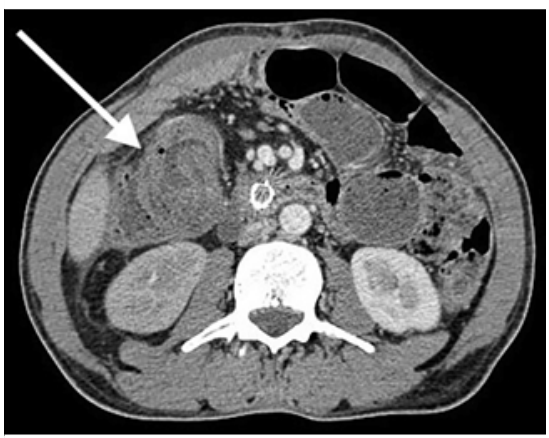

Fig. 1 Computed tomography scan of the abdomen showing colocolic intussusception, with the target sign (arrow).

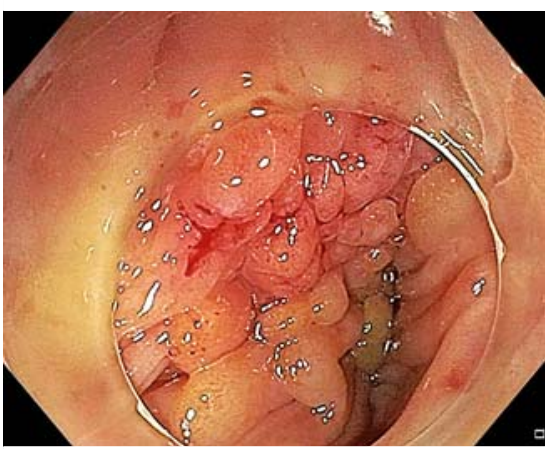

- Fig. 2 Endoscopic image of the infiltrated segment at the hepatic flexure of the colon, which was acting as the lead point for the intussusception.

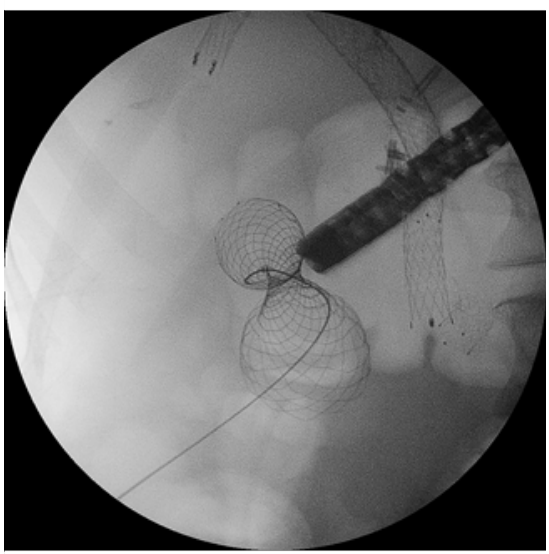

- Fig.3 Fluoroscopic image showing the colonic self-expanding metal stent deployed over the guidewire.
A 47-year-old man with a history of gastric cancer, initially treated by subtotal gastrectomy, with subsequent recurrence in the periampullary region and peritoneal metastases, presented with abdominal distension and obstipation for 3 days. He was started on intravenous hydration and kept nil per os. A computed tomography (CT) scan of the abdomen showed involution of the right-sided colon and neighboring peritoneal thickening, with a target sign, and dilated cecum and small-bowel loops, suggestive of right-sided colocolic intussusception ( Fig. 1).

In view of his metastatic disease, the patient was referred for colonoscopy and decompression. Colonoscopy was done with a distal transparent attachment using a flushing pump. Edematous infiltrated mucosa, with involuted bowel and luminal narrowing was seen at the hepatic flexure. The colonoscope was negotiated beyond the narrowing with gentle manipulation (> Fig.2). A $25 \times 90-\mathrm{mm}$ WallStent colonic self-expanding metal stent (SEMS; Boston Scientific, Marlborough, Massachusetts, USA) was placed

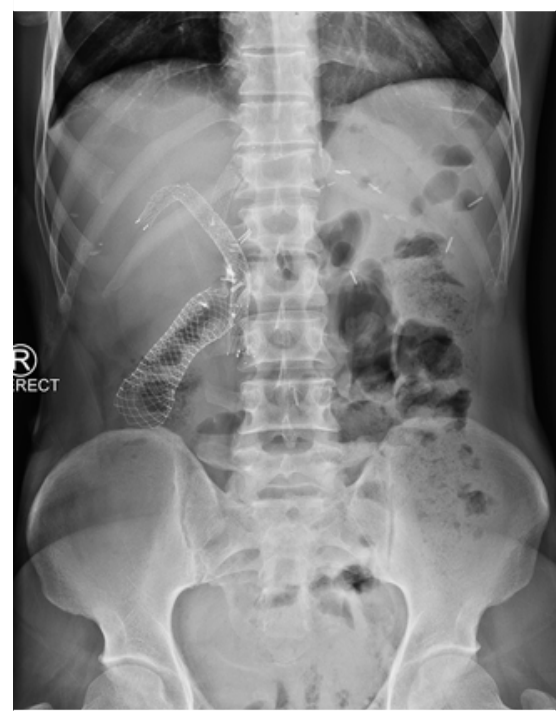

Fig. 4 Plain radiograph of the abdomen post-stent placement showing the expanded colonic stent and no evidence of bowel dilatation, with a biliary self-expanding metal stent also visible.

across the narrowing under fluoroscopic guidance ( $>$ Fig. 3 ; $>$ Video 1 ). The distal end of the stent was fixed with clips. The patient improved with free passage of
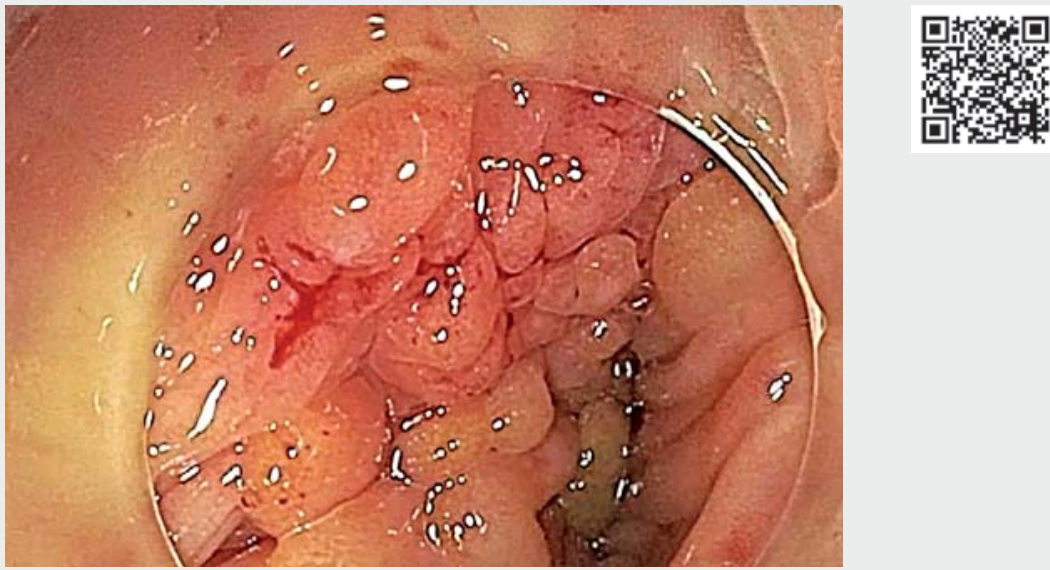

$\checkmark$ Video 1 Management of colocolic intussusception in an adult by placement of a colonic stent. 
stools and flatus. Plain radiography of the abdomen on the evening of the procedure showed the expanded SEMS, with no evidence of dilated bowel ( $>$ Fig. 4 ).

Intussusception is a rare cause of colonic obstruction, with the colon accounting for $5 \%$ of all instances of intussusception [1]. In adults, about half of bowel intussusceptions result from malignancy, with surgical resection being required in $72 \%$ of patients [2]. Endoscopic management of ileocecal intussusception with hyperinsufflation at the lead point has been described previously [3]. In adults, intussusception is managed mostly with surgery, unlike in children where it is managed conservatively [4], although recurrence of intussusception is known to occur in up to $20 \%$ children after conservative management [5]. In this case, SEMS placement was planned to prevent recurrent episodes of intussusception as surgery was deferred owing to the metastatic disease. To the best of our knowledge, no previous reports of the endoscopic management of colocolic intussusception are available.

\section{Endoscopy_UCTN_Code_TTT_1AQ_2AF}

\section{Competing interests}

The authors declare that they have no conflict of interest.
The authors

\section{Raosaheb Rathod, Sridhar Sundaram, Aadish Kumar Jain, Kiran Mane, Prachi Patil, Shaesta Mehta}

Department of Digestive Diseases and Clinical Nutrition, Tata Memorial Hospital, Mumbai, India

\section{Corresponding author}

Raosaheb Rathod, MD, DM

Department of Digestive Diseases and Clinical Nutrition, Tata Memorial Hospital, Homi Bhabha National Institute, Dr. E Borges Road, Parel, Mumbai 400012, India rtrathod151@gmail.com

\section{References}

[1] Wilson A, Elias G, Dupiton R. Adult colocolic intussusception and literature review. Case Rep Gastroenterol 2013; 7: 381-387

[2] Barussaud M, Regenet N, Briennon X et al. Clinical spectrum and surgical approach of adult intussusceptions: a multicentric study. Int J Colorectal Dis 2006; 21: 834-839

[3] Averbach M, de Rezende Zago R, Popoutchi $P$ et al. Adult ileocolic intussusception: endoscopic treatment. Gastrointest Endosc 2015; 81: 464-465

[4] Khan Z, Darr U, Renno A et al. Transient descending colonic intussusception due to a large fecaloma in an adult. ACG Case Rep J 2017; 4: e94

[5] Hsu WL, Lee HC, Yeung CY et al. Recurrent Intussusception: when should surgical intervention be performed? Pediatr Neonatol 2012; 53: 300-303
Bibliography

Endoscopy 2022; 54: E464-E465

DOI 10.1055/a-1625-5105

ISSN 0013-726X

published online 27.9.2021

(C) 2021. Thieme. All rights reserved.

Georg Thieme Verlag KG, Rüdigerstraße 14 , 70469 Stuttgart, Germany

ENDOSCOPY E-VIDEOS

https://eref.thieme.de/e-videos

回局 Endoscopy E-Videos is an open access online section, 自解: reporting on interesting cases and new techniques in gastroenterological endoscopy. All papers include a high quality video and all contributions are freely accessible online. Processing charges apply (currently EUR 375), discounts and wavers acc. to HINARI are available.

This section has its own submission website at https://mc.manuscriptcentral.com/e-videos 